\title{
Noonan syndrome with CT-scan evidence of brain atrophy and ventriculomegaly
}

\section{Aamir Jalal Al Mosawi}

Advisor in Pediatrics and Pediatric Psychiatry Children Teaching Hospital of Baghdad Medical City, Iraq

Corresponding author: Aamir Jalal Al Mosawi, Advisor in Pediatrics and Pediatric Psychiatry Children Teaching Hospital of Baghdad Medical City, Iraq. Email: almosawiAJ@yahoo.com

Received date: November 28, 2019; Accepted date: December 06, 2019; published date: December 10, 2019

Citation: Aamir Jalal Al Mosawi. Noonan syndrome with CT-scan evidence of brain atrophy and ventriculomegaly.JClinical Research and Reports, 1(1); DOI: 10.31579/JCRR/2019/003

Copyright: () 2019 Aamir Jalal Al Mosawi. This is an open access article distributed under the Creative Commons Attribution License, which permits unrestricted use, distribution, and reproduction in any medium, provided the original work is properly cited.

\section{Abstract}

Background: Noonan syndrome is congenital syndrome that occur sporadically or inherited as an autosomal dominant disorder, and is associated with a wide spectrum of clinical manifestations that vary greatly in range and severity including facial dysmorphism with low set ears, bulbous nose, micrognathia, and thick upper eyelids, mental retardation, nuchal folding, a low posterior hairline, high arched palate and widely space nipples. Cerebral abnormalities have been rarely associated with this syndrome. The aim of this paper is report the rare occurrence of cerebral abnormalities in an Iraqi girl with Noonan syndrome.

Methods: A ten month girl with dysmorphic features, growth retardation and psychomotor retardation was studied. Results: The girl had a sporadic form of Noonan with predominant cerebral manifestations and without congenital heart defect. She had growth and psychomotor retardation, hypotonia, craniofacial dysmorphism with low set ears, bulbous nose, thick upper eyelid, high arched palate, and micrognathia. She also had widely space nipples, nuchal folding and a low posterior hairline. CT-scan showed ventriculopathy with evidence of brain atrophy.

Conclusion: This paper reported a very rare association of Noonan syndrome with CT-scan evidence of ventriculopathy and brain atrophy in an Iraqi girl.

Keywords: noonan syndrome; cerebral manifestations; ventriculomegaly; brain atrophy

\section{Introduction}

Noonan syndrome is a heterogeneous congenital syndrome that occur sporadically or inherited as an autosomal dominant disorder. It is associated with a wide spectrum of clinical manifestations that vary greatly in range and severity. The disorder is generally associated with a distinctive facial appearance including, low set ears, bulbous nose, a small jaw (micrognathia), and thick upper eyelids. The syndrome is also commonly associated with nuchal folding, a low posterior hairline, and high arched palate and widely space nipples. The syndrome is associated with variable degree of mental retardation. Many infants with Noonan syndrome also have heart (cardiac) defects which can help in making early diagnosis. Cerebral abnormalities have been rarely associated with this syndrome [1-9]. The aim of this paper is report the rare occurrence of cerebral abnormalities in an Iraqi girl with Noonan syndrome.

\section{Materials and methods}

A ten month girl with dysmorphic features, growth retardation and psychomotor retardation was studied.

\section{Results}

\section{The girl had the following features:}

1-Poor feeding, and growth retardation.

2-Hypotonia with poor head control and delayed sitting (Figure-1).

3-Psychomotor retardation with poor awareness to the surrounding(Figure-1). 4-Craniofacial dysmorphism with low set ears, bulbous nose, thick upper eyelids (Figure-2), high arched palate, and micrognathia (Figure-3).

5-Widely space nipples (Figure-4).

6-Nuchal folding and a low posterior hairline.

The parents were health and the case was sporadic.

Echocardiography showed normal finding and CT-scan showed ventriculopathy with evidence of brain atrophy.

Chromosomal analysis showed normal female karyotype. 
J Clinical Research and Reports

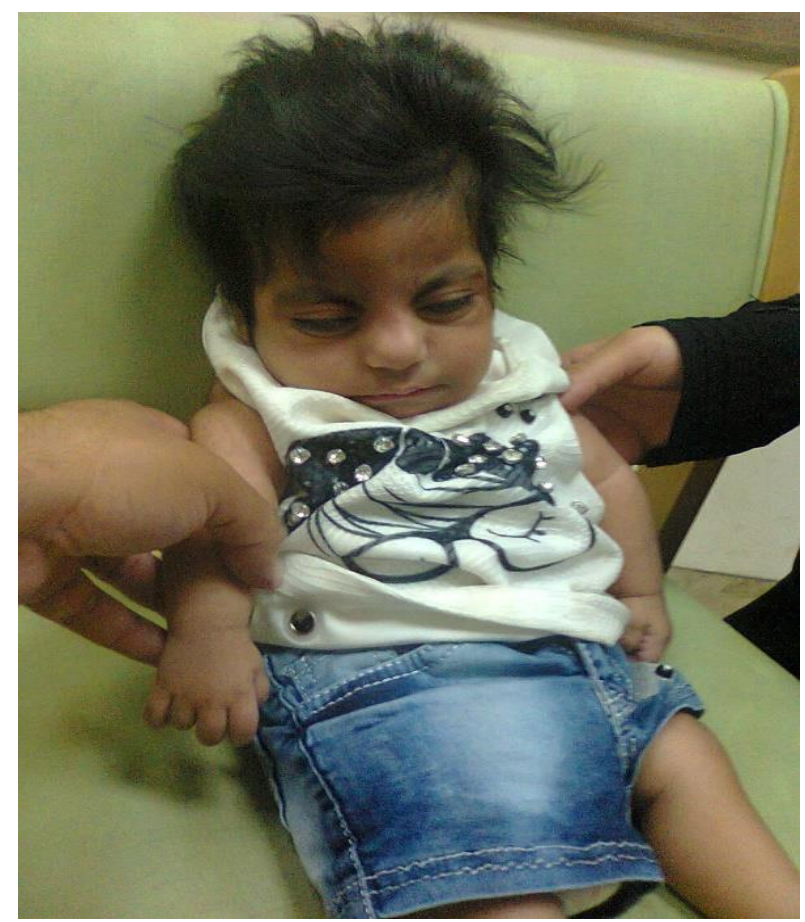

Figure-1: The girl was hypotonia with poor head control and delayed sitting and had poor awareness to the surrounding

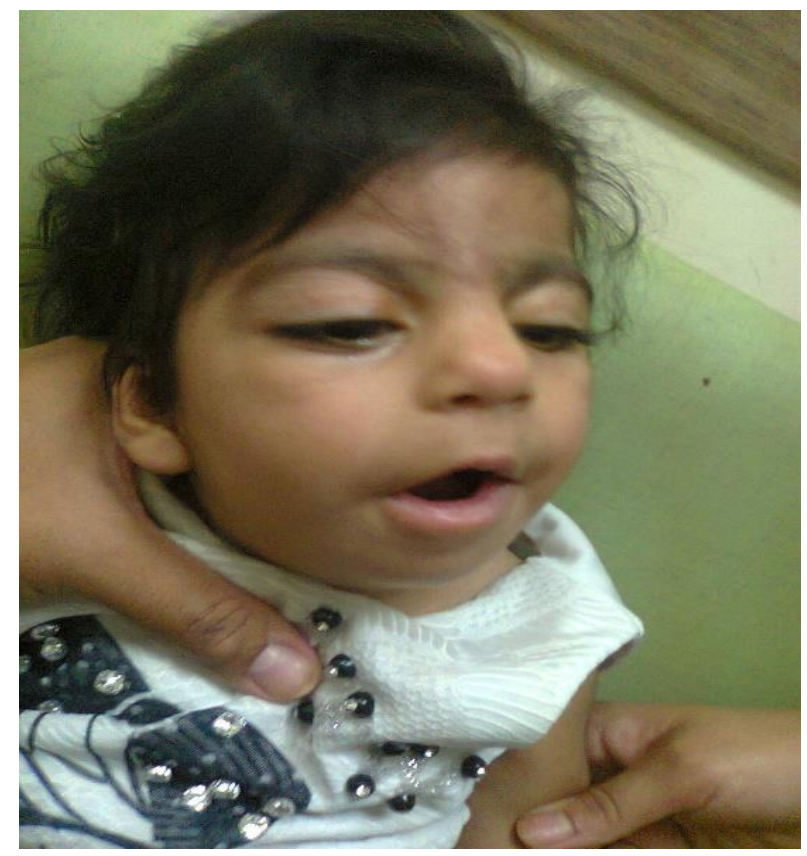

Figure-2: The girl had craniofacial dysmorphism with low set ears, bulbous nose, thick upper eyelids

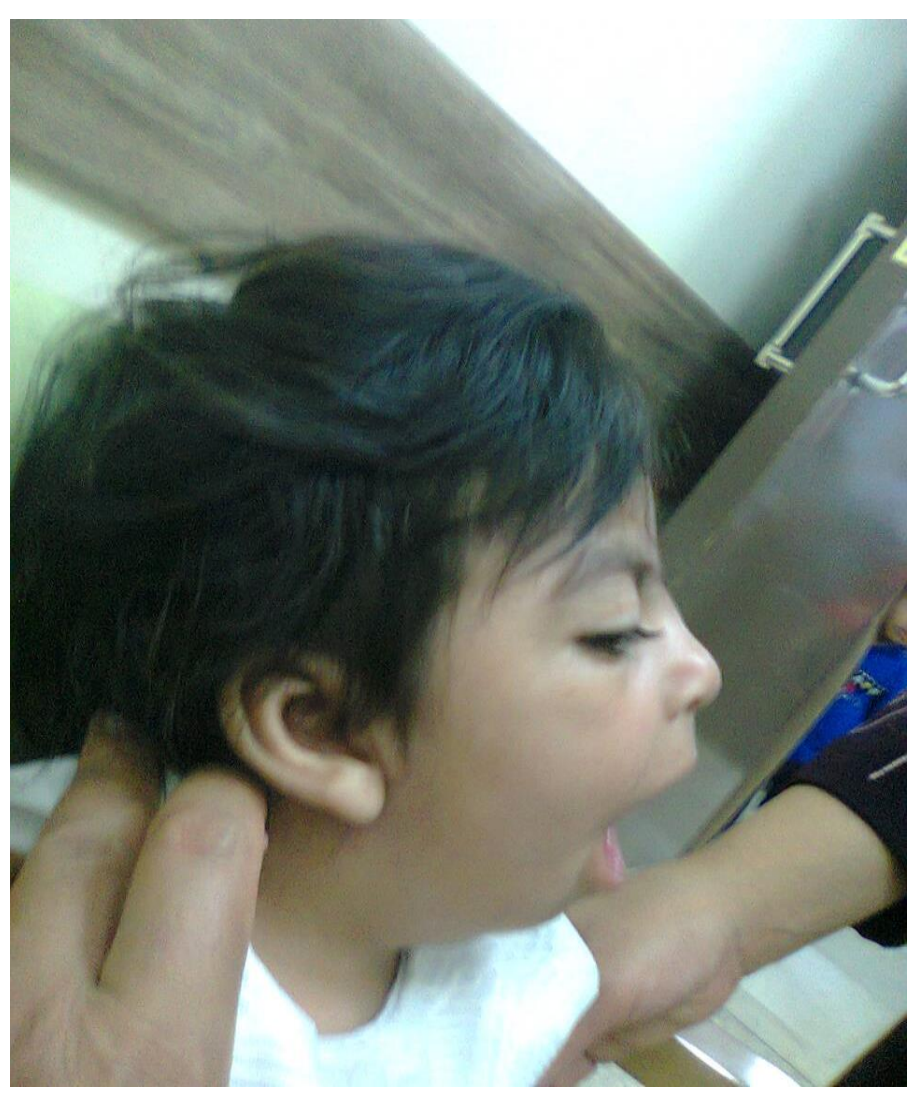

Figure-3: The girl also had a small jaw (micrognathia)

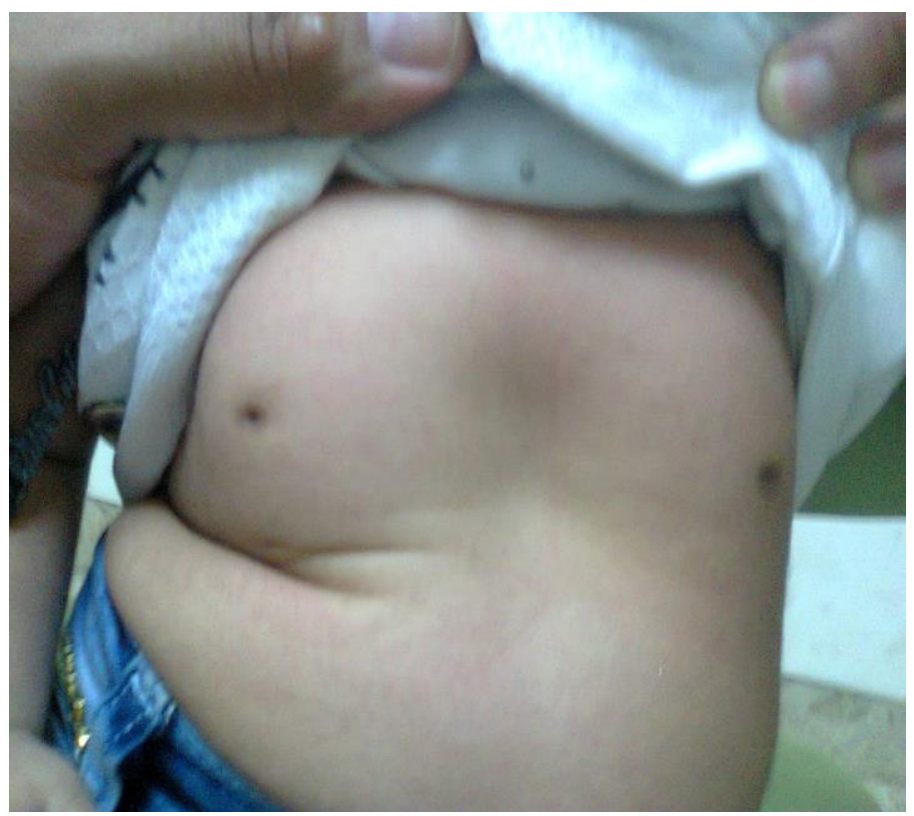

Figure-4: The girl had widely space nipples 


\section{Discussion}

Cerebral abnormalities have been rarely associated with Noonan syndrome [2-9]. Heye and Dunne (1995) reported the association of Noonan syndrome with hydrocephalus, hindbrain herniation, and upper cervical intracord cyst [5].

Henn et al (1997) from Germany reported four patients from three subsequent generations of a family with autosomal dominant Noonan syndrome associated pulmonary valve stenosis, craniofacial dysplasia with marked hypertelorism and, a variable occurrence of progressive hydrocephalus [6].

Brasil et al (2010) from Bazil reported the association of Noonan syndrome with cerebral abnormalities including isolated ventriculomegaly, posterior fossa anomalies, and cerebral atrophy in infants [7].

Zarate et al (2014) from the USA reported a six-year-old boy with Noonan syndrome associated with Chiari malformation type I and cerebrovascular changes [8].

Spennato and colleagues (2019) from Italy reported a five-year old with boy an unusual association of Noonan syndrome and tetraventricular hydrocephalus, caused by fourth ventricle outlet obstruction. Magnetic resonance imaging showed a diverticular enlargement of the left foramen of Luschka, with compression of the facial nerve that resolved following treatment of hydrocephalus by endoscopic third ventriculostomy[9].

Conclusion: This paper reported a very rare association of Noonan syndrome with CT-scan evidence of ventriculopathy and brain atrophy in an Iraqi girl.

\section{Acknowledgement}

The author would to express his gratitude for the parents of the patient who accepted publishing her photos.

\section{References}

1. Noonan JA (1968) Hypertelorism with Turner phenotype: a new syndrome with associated congenital heart disease. Am Dis Child; 116:373-80.

2. Duenas DA, Preissig S, Summitt RL, Wilroy RS, Lemmi H (1973) Neurologic manifestations of the Noonan syndrome. PMID: 4687589. South Med J Feb;66(2):193-6.

3. Ball MJ, Peiris A (1982) Chiari (type 1) malformation and syringomyelia in a patient with Noonan's syndrome. J Neurol Neurosurg Psychiatry; 45:753-4.

4. Kobayashi I, Aikawa T, Takemiya T, Maruyama S, Takano K (1986) Noonan's syndrome with syringomyelia. J Psychiatry Neurol; 40:101-4.

5. Heye N, Dunne JW (1995) Noonan's syndrome with hydrocephalus, hindbrain herniation, and upper cervical intracord cyst. J Neurol Neurosurg Psychiatry Sep; 59(3):338-9. PMID:7673972.

6. Henn W, Reichert H, Nienhaus H, Zankl M, Lindinger A et al (1997) Zang KD.Progressive hydrocephalus in two members of a family with autosomal dominant Noonan phenotype. Clin Dysmorphol Apr ;6(2):153-6. PMID: 9134296.

7. Brasil AS, Pereira AC, Wanderley LT, Kim CA, Malaquias AC et al (2010) PTPN11 and KRAS gene analysis in patients with Noonan and Noonan-like syndromes. Genet Test Mol Biomarkers Jun;14(3):425-32. PMID: 20578946.

8. Zarate YA, Lichty AW, Champion KJ, Clarkson LK, Holden KR et al (2014) Unique cerebrovascular anomalies in Noonan syndrome with RAF1 mutation. J Child Neurol Aug; 29(8):NP13-7.

9. Spennato P, Sacco M, Cinalli G (2019) diverticular dnlargement of foramen of Luschka and hydrocephalus in child with Noonan syndrome. World Neurosurg May; 125:371-373. 